\title{
JUURNAL.RU
}

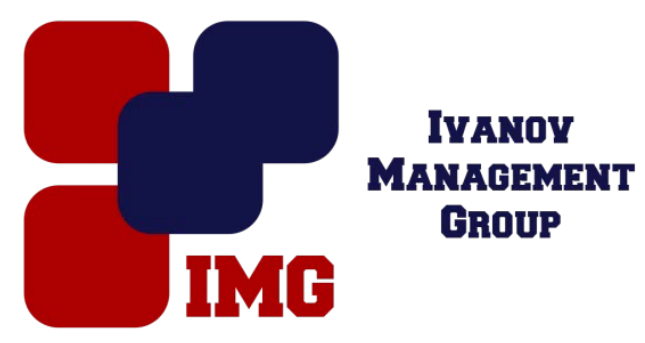

Большаков А.Г., Лоншаков Д.А. Белгородский государственный технологический университет им. В.Г. Шухова Белгород, Россия

doi: 10.18411/lj-25-12-2016-1-13

idsp 000001:lj-25-12-2016-1-13

\section{Цена жилья и градостроительные свойства районов размещения (на примере Белгорода)}

\section{Аннотация}

Рассматривается взаимосвязь цены жилья на типовую застройку и качества районов ее размещения. В качестве индикатора распределения цены жилья по городу принят жилой дом 91 серии, по той причине, что такая застройка представлена в большинстве районов города. Под качеством микрорайонов и районов понимается насыщенность территории объектами социальной инфраструктуры и их доступность. Сопоставление рейтингов районов на материале Белгорода со стоимостью типовой жилой застройки, в них расположенной, дало возможность подтвердить закономерность: потребительная стоимость жилища возрастает за счет повышения градостроительного качества районов. На материале Белгорода корреляция по разным районам составила $75 \%$

Ключевые слова: Типовая застройка; индикатор качества районов; рейтинг районов; насыщенность и доступность объектов социальной инфраструктуры; сопоставление рейтингов районов и цены жилья

\section{Взаимосвязь градостроительной и архитектурной ценности застройки}

Каждое здание помимо архитектурной ценности, обладает также градостроительной ценностью, которая отображает значимость занимаемой зданием территории и привлекательные условия местоположения. Градостроительная ценность района размещения носит многокомпонентный характер - это показатели транспортной инфраструктуры, комплексного благоустройства, фактической приближенности к городскому центру, социальной инфраструктуры и т. д. Концепция т.н. Нового урбанизма декларирует - в шаговой доступности от жилья должны располагаться места приложения труда, общественный центр, рекреация, школа и другие объекты социальной инфраструктуры [1]. Обоснованность таких тезисов становится всё очевиднее в наше время - время информационного общества. Новые проекты не всегда учитывают эти (принципы нового урбанизма) положения. Но каждый район оценивается степенью центральности. Рем Колхас утверждает, что большие разрывы в степени "центральности" между районами города ведут к ряду 
градостроительных проблем: концентрации строительного объёма в одной месте, социальной сегрегации и т.д. Вместе с тем, центр накапливая свой потенциал, со временем распределяет его и на остальные районы. Так происходит усложнение городской структуры и функционального разнообразия [ 2 ].

Таким образом, именно развитость социальной инфраструктуры в наибольшей степени характеризует градостроительную ценность района и его потенциал к "центральности", когда жители района смогут удовлетворить основные потребности на месте. Под развитостью социальной инфраструктуры мы понимаем во-первых насыщенность района объектами - детскими садами, школами, поликлиниками и т.д. Во-вторых, доступность этих объектов для жителей, что является немаловажным фактором в градостроительном развитии города [ 3 ]. Далее, чтобы определить градостроительную ценность жилой территории города, предлагается воспользоваться методом ранжирования. Так, следует выделить жилые районы и сопоставить их между собой. На примере г. Белгорода, разбивка жилой застройки на достаточно самостоятельные районы жилые кластеры, была проведена в работе по оценке функциональной насыщенности [4].

Как показывают исследования социальной морфологии города, жилая среда, несмотря на общее усложнение функциональной структуры города, приобретает всё более гомогенный характер и локализуется в планировке города дискретно, однако зачастую в пределах одного района [ 5 ]. Гомогенность жилой среды выражается в стремлении богатых социальных групп обособиться, но чаще это достигается архитектурными средствами, нежели градостроительными, в чём и состоит дискретный характер распределения таких групп в городской застройке.

Социальные факторы в формированию нового жилья на уровне квартир и домов рассматриваются в работе Благовой М. В., которая учитывает, с одной стороны тип семьи и уровень доходов населения, и, с другой стороны, предлагает дифференциацию жилья на классы в соответствии имущественному цензу домовладений, а комнатность квартир ставит в соответствие с количеством членов семьи[ 6]. Однако зависимость структуры и ценности жилища от градостроительного качества районов размещения остаётся по-прежнему недостаточно изученной темой, что объясняет актуальность настоящего исследования, которое ко всему прочему даёт количественную оценку этой зависимости.

Встаёт вопрос о методе определения градостроительной ценности районов с помощью идентичного для всех районов показателя. В нашем исследовании таким показателем принимается коммерческая стоимость типового жилья. Типовое жильё исключает влияние архитектурных факторов и позволяет более точно определить градостроительную ценность района. Итак, утверждается, что на социальную эффективность района влияет в первую очередь развитость социальной инфраструктуры. Для того чтобы подтвердить это необходимо установить корреляцию между рейтингами районов по коммерческой стоимости типового жилья и развитости социальной инфраструктуры.

\section{Локализация типовой жилой застройки в плане города}

В застройке Белгорода, наибольшее распространение получили две типовые серии - 434 и 91, в меньшей степени представлена 464 серия (рис.1, рис.2) 


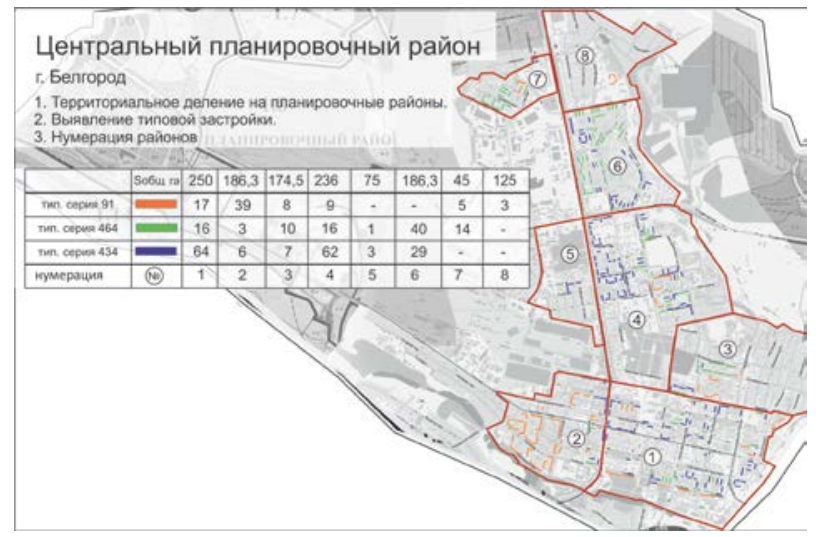

Рис. 1 Локализащия типовой жилой застройки в Центральном планировочном районе

Локализация типовой застройки в плане города была выявлена при помощи натурных обследований, а также средствами программы Google Earth на основе спутниковой съёмки. Архитектурно-планировочная характеристика жилья типовых серий показала более сбалансированный баланс квартирографии и социальную доступность относительно новой жилой застройке.

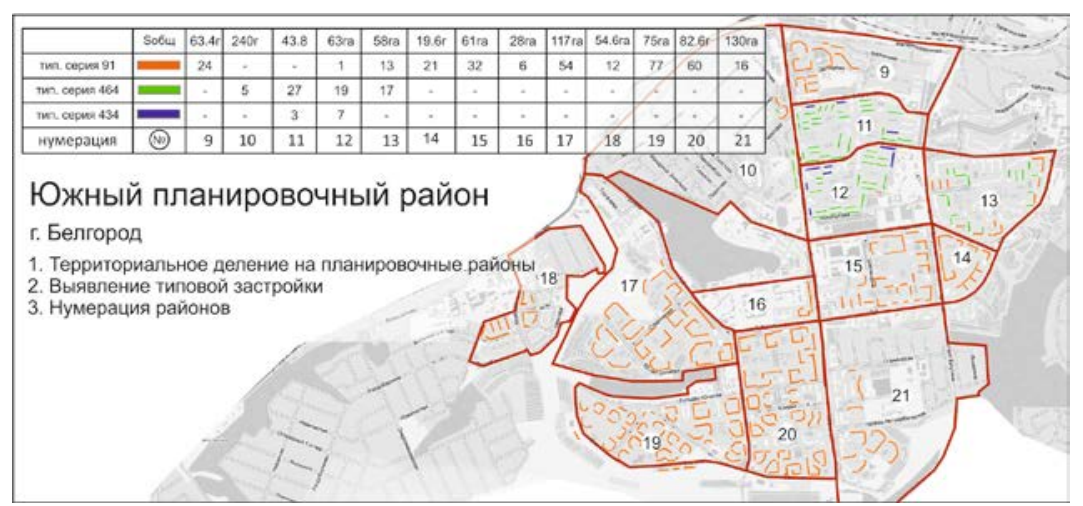

Рис. 2 Локализаџия типовой жилой застройки в Южном планировочном районе

\section{Оценка районов с типовой жилой застройкой по насыщенности и доступности объектов социальной инфраструктуры}

В расчет принимались школы, детские сады, магазины, места приложения труда, поликлиники. По насыщенности данными объектами на площадь района первое место в рейтинге занял центральный район (57 объектов, кол-вообъектов/ Sобщ), второе - микрорайон Гринёвка; третье место - у района в границах улиц Белгородский проспект, Студенческая, Попова пригруженного территорией Мелзавода. Общую характеристика районов представлена на рис. 3,4.

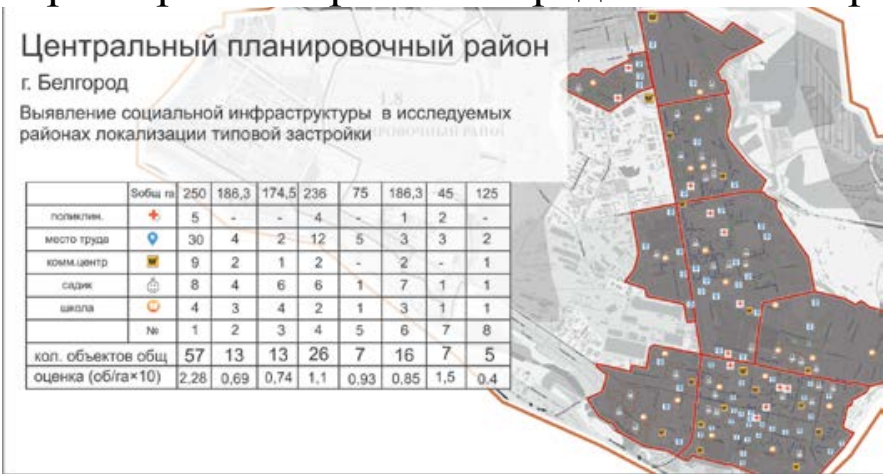

Рис. 3 Развитость социальной инфраструктуры в Центральном планировочном районе 


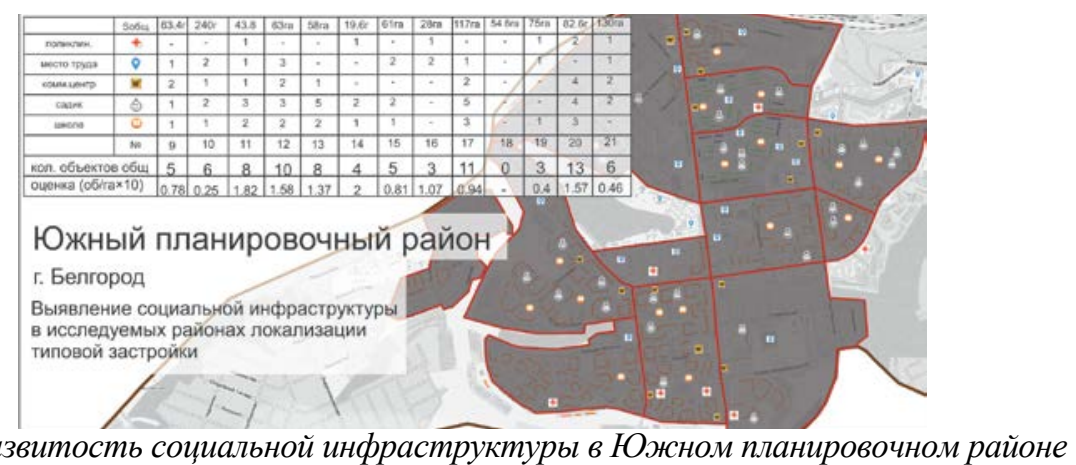

Рис. 4 Развитость социальной инфраструктуры в Южном планировочном районе

Применённый метод показал небольшую проблему: районы с малой площадью попадают в более выгодные условия при таком ранжировании. Очевидно, что простым подсчетом распределения объектов соцкультбыта на площадь района, без учета т.н. веса объектов нельзя точно установить место района в рейтинге. Но в виду приблизительной сопоставимости большинства районов по площади, рейтинг достаточно точно отображает градостроительный аспект социальной инфраструктуры. К тому же, целью данного исследования является не столько достоверное установление рейтингов, сколько общая логика и методика градостроительного анализа социальной эффективности территории.

Далее был установлен рейтинг исследуемых районов в зависимости от степени доступности/удаленности школ, детских садов и поликлиник со стороны размещенных в районах домов 91 и 464 серии. Методика определения доступности представляет классическое сопоставление радиусов удалённости объектов. Вокруг объектов описаны окружности с заданным радиусом. Дома типовых серий, попадающие в один из этих кругов, оцениваются как удаленные, доступные или близко расположенные (рис. $5,6,7)$

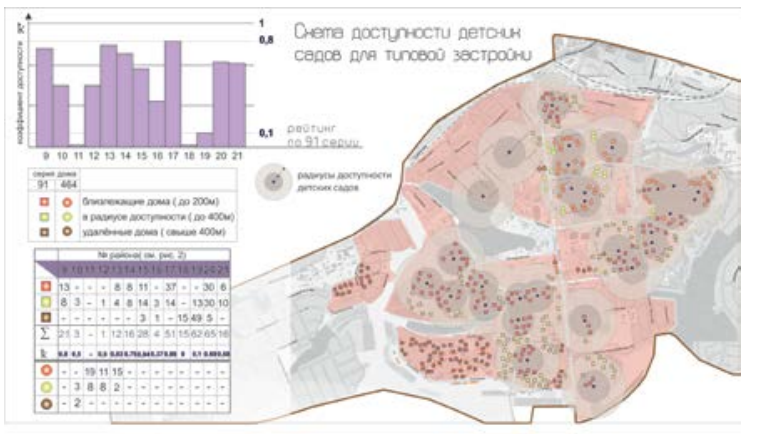

Рис. 5 Доступность социальной инфраструктуры на примере детских садов и типовой застройки 91 и 464 серий. Южный планировочный район, г. Белгород.

91 серия наиболее равномерно распределена на территории исследуемых районов. В связи с этим, именно 91 серия представляет наибольший интерес для исследования взаимозависимости стоимости жилья и социальной инфраструктуры. Так 91 типовая серия локализована преимущественно в Южном планировочном районе, приведём примеры исследования этого району в виду наибольшей наглядности (см. рис. 5,6,7)

Рейтинг доступности рассчитан на примере 91 серии. Для подсчёта степени доступности социальной инфраструктуры в виде заданных объектов используется простое деление общего количества домов в районе на сумму близлежащих и доступных( с коэффициентом 0,5) домов. Таким образом каждый район получает количественную оценку, характеризующую сравнительную степень доступности 
социальной инфраструктуры. Расчёт для всех объектов социальной инфраструктуры одинаков, меняются только дестинации и радиусы их доступности. Дестинациями выступают точки притяжения - объекты социального обеспечения, а локациями - точки отсчёта - типовая застройка[ 7 ].

В исследуемых планировочных районах располагается 63 детских сада, 29 из них в Южном планировочном районе (рис.5). Вокруг садов описаны радиусы в 200 и 400 м. Обеспеченность детскими садами носит наиболее равномерный в пространственном отношении характер. Несмотря на это, есть районы с острым дефицитом: мкр11 - район по ул. Есенина (№ 19 на рис.2), а также район по ул. Магистральная (№ 18 на рис. 2). Исследуемый район под номером 18 по ул. Магистральной вообще не обладает какой-либо социальной инфраструктурой, а также находится на отдалении от общего блока жилых районов, вне зоны доступности социальной инфраструктуры других районов. Этот район представляет очевидный образец градостроительной проблематики. Наилучшее значение показателей наблюдается в районах под номерами 11, 12, 13, 14, 20 (см. рис.2)

Среднеобразовательные учреждения имеют радиусы доступности 300 и 600 м. Наибольший дефицит наблюдается в т.н. районе "Луч" (№ 21). Также недостаток наблюдается в районе по ул. Есенина. в остальных районах наблюдается равномерное распределение школьных услуг.

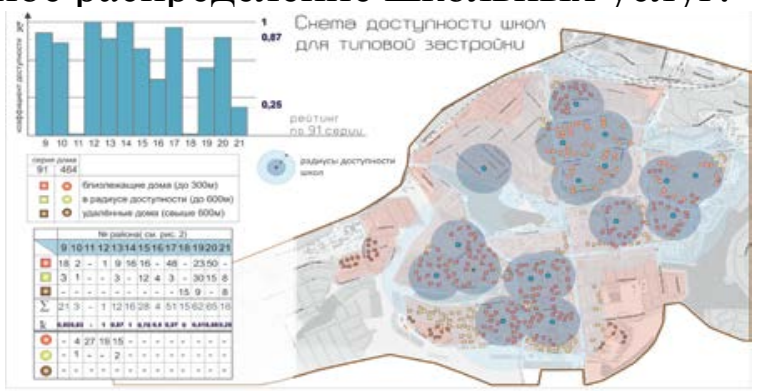

Рис. 6 Доступность соииальной инфраструктуры на примере школ и типовой застройки 91 и 464 серий. Южный планировочный район, г. Белгород

На рис. 7 представлен пример расчёта доступности услуг социального здравоохранения. Радиусы действия поликлиник приняты в 400 и 800 м. На весь Южный планировочный район приходится всего 5 поликлиник, которые сосредоточены в противоположность общей тенденции в южных районах, обладающих дефицитом по отношению к другим объектам социальной инфраструктуры.

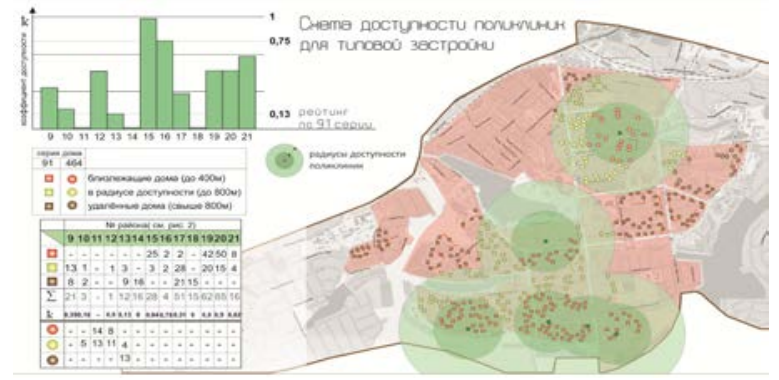

Рис. 7 Доступность соииальной инфраструктуры на примере поликлиник и типовой застройки 91 и 464 серий. Южный планировочный район, г. Белгород.

Далее опускаем оценку районов по доступности социальной инфраструктуры для Центрального планировочного района, которая выполнена по аналогичной методике . В итоге достигнут результат ранжирования всех районов, 
в которых встречается типовая застройка 91 серии.

Всего в городе было выделено 16 районов. Все они единообразно были ранжированы по насыщенности социальной инфраструктурой и по степени покрытия застройки услугами объектов соцкультбыта. Тем самым планировочные районы выстроились в единый рейтинг, который затем необходимо соотнести с распределение коммерческой стоимости.

\section{Общегородской рейтинг районов по коммерческой стоимости типового}

\section{жилья}

По материалам открытой базы данных интернет-ресурса [8], посвящённого недвижимости, установлена средняя цена квадратного метра типовой застройки 91 и 464 серий (см. табл. 1).

Таблица 1.

Стоимость жилой застройки 1-464 и 91 серий г. Белгорода

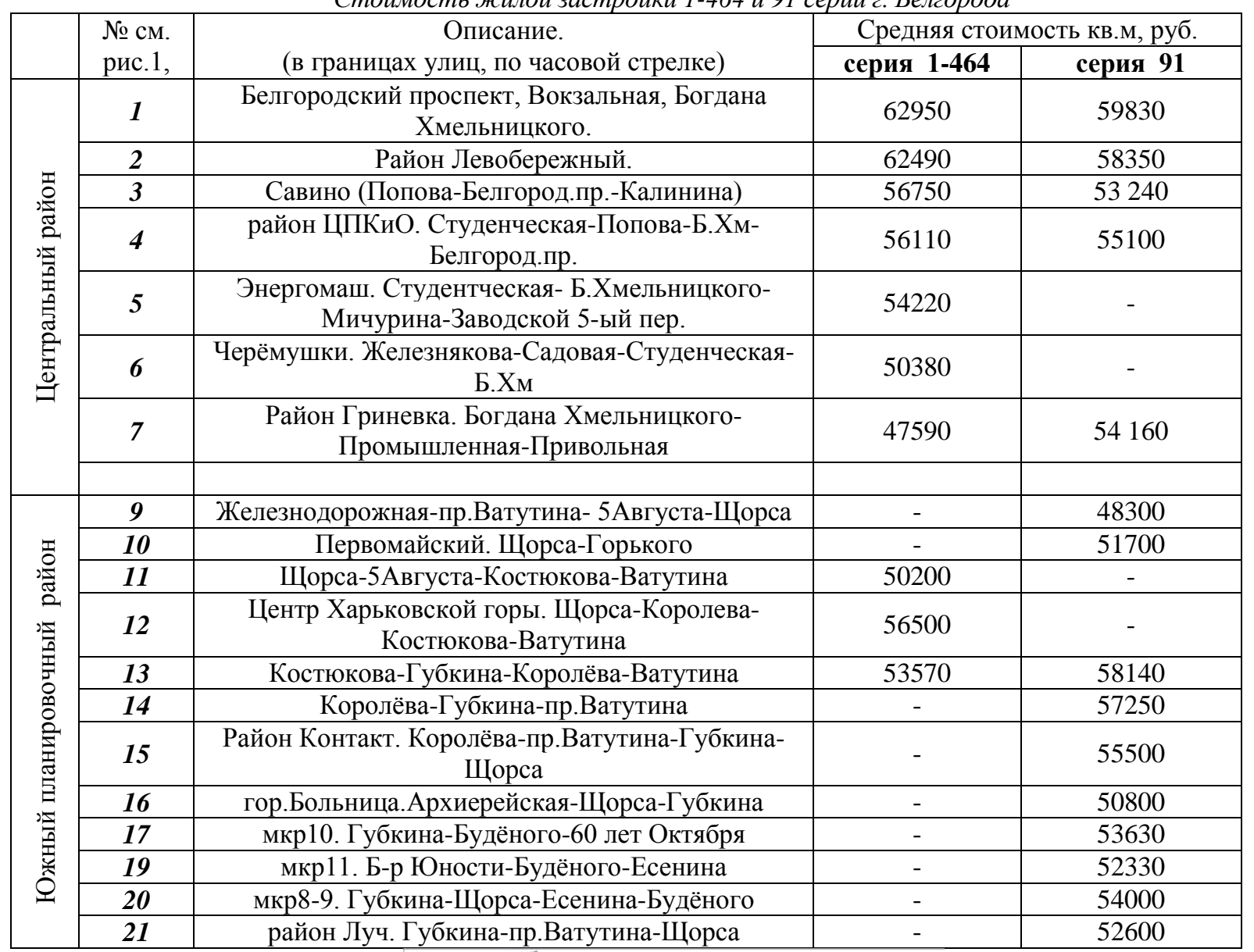

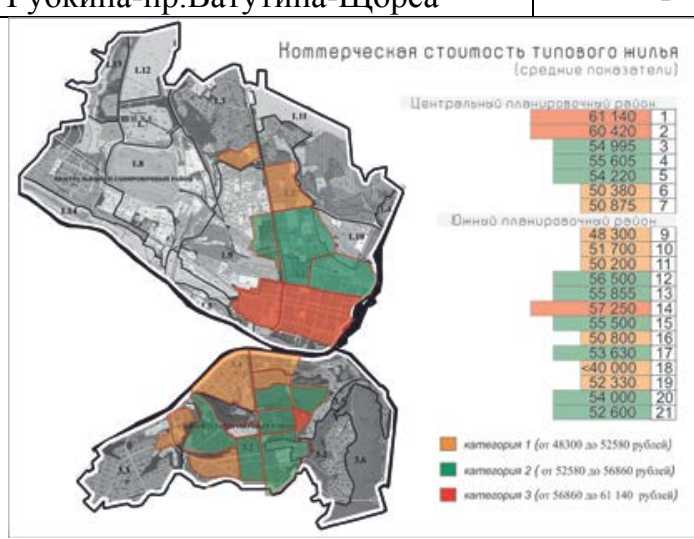

Рис. 8 Распределение средней стоимости 1 кв.м. типового жилья, г. Белгород. 
Для картографического отображения распределения средней стоимости спектр цен поделен на три категории: 1) от 48300 до 52580 рублей; 2) от 52580 до 56860 рублей; 3) от 56860 до 61140 рублей. Расположения домов 464 и 91 серий (то есть одинаковых квартир) в районах, где квартиры приобретают дополнительную потребительную стоимость, либо теряют часть этой стоимости, выделяется на карте цветом. Первая категория - оранжевый цвет, вторая категория - зеленый цвет, третья категория - красный цвет.

Сопоставление рейтингов районов по насыщенности и доступности объектов социальной инфраструктуры и стоимости жилья в данных районах

Теперь можно сопоставить рейтинг районов по обеспеченности объектами социальной инфраструктуры, с одной стороны, и стоимость квадратного метра жилой застройки 91 серии, с другой стороны. См.Рис 9. Полученные данные подтверждают наличие корреляции между ценой квадратного метра застройки с одной стороны и уровнем обеспеченности социальной инфраструктурой районов с другой. Общий уровень корреляции составил 75\%, что является хорошим подтверждением выдвинутой изначально гипотезы: в хорошем районе жильё дороже, в тоже время качество района во многом обусловлено показателями развитости социальной инфраструктуры.

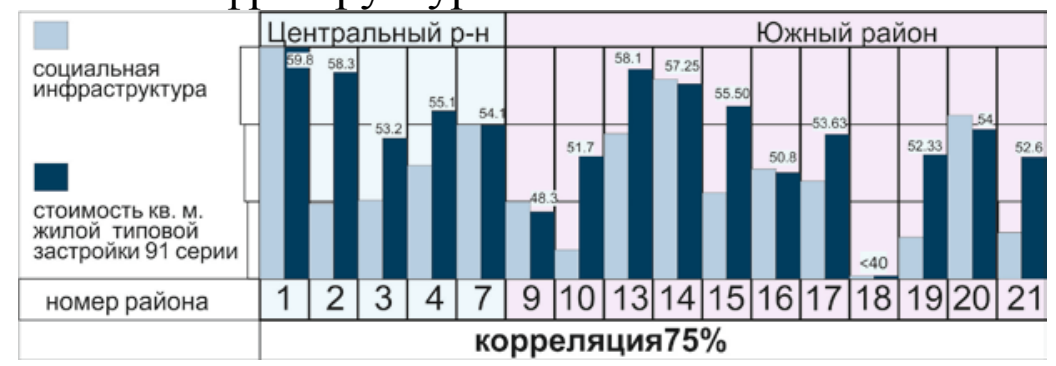

Рис. 9. Корреляциия несоизмеренных рейтингов - рейтинга районов по обеспеченности объектами соикультбыта и стоимости квадратного метра жилья 91 серии. г. Белгород.

Заключения

Жилой фонд Белгорода составляют дома трёх основных серий типовой застройки, одна из которых (91-ая) является непосредственной разработкой региона. Размещение разных типов жилой застройки характеризуется тенденцией концентрированной застройки районов преимущественно одной типовой серией. (91,363, 464).

Для выявления зависимости цены квадратного метра жилья от градостроительных условий, представленных в разных микрорайонах города, правильнее воспользоваться как измерителем одним типом дома, который представлен в большинстве микрорайонов города. Таким типом для Белгорода является дом 91-ой серии.

По условиям доступности и насыщенности микрорайонов города объектами социальной инфраструктуры проведен анализ и составлен рейтинг местоположений (микрорайонов).

По данным сайтов недвижимости стоимость домов 91-ой серии представлена в широком диапазоне от 40 тыс. руб. за 1 кв. м до 62 тыс. руб. за 1 кв.м. При этом технико-экономические и архитектурно-планировочные условия квартир не составляют значимой разницы.

Разница в потребительной стоимости жилья (рыночной стоимости) зависит от градостроительного качества микрорайонов (исследована укомплектованность объектами социальной инфраструктуры и их доступность). По результатам 
выполненного соотнесения рейтингов местоположений и рейтингов домов корреляция составляет $75 \%$.

Это говорит о закономерности в повышении социальной эффективности жилья путем градостроительного развития микрорайонов в отношении их функционального разнообразия и уплотнения социальной инфраструктуры. *

Работа выполнена при финансовой поддержке РФФИ проект №14-41-08051

\section{Литература}

1. Andres Duany, Elizabeth Plater-Ziberk and Jeff Speck Suburban Nation: The Rise of Sprawl and the Decline of the American Dream. New York: North Point Press, 2000. 294 pp.

2. Рем Колхас. Город-генерик. М.- Арт Гид, 2015.-84 стр. (17-51).

3. Клевакин А.Н. Сибирский город в эпоху перемен / А.Н. Клевакин.Новосибирск: Наука, 2008.-116 с.

4. А.Г. Большаков, Д.А. Лоншаков, В.Ю. Бондарева, Т.П. Щербакова. Оценка взаимосвязи социальных и пространственных факторов в планировке города Белгорода, Вестник ИрГТУ №1 2015, с.88-102.

5. Н.А. Самойлова, О.Н. Стрижакова. «Богатство» и «бедность»: контрасты полярных пространств города (на примере Самары и Нижнекамска).

6. Благова М. В. Архитектурное формирование коммерческого жилища на социальнофункциональной основе .- Автореф. диссертации на соискание ученой степени кандидата архитектуры.- Н.Новгород: ННГАСУ, 2016. - 24 с.

7. Большаков А.Г., Лоншаков Д.А. Ландшафтно-планировочные принципы организации рекреации на основе овражно-прудового ландшафта в Белгородском пригородном районе // Вестник ИрГТУ, №2(85), 2014. -c. 117-126.

8. Стоимость квадратного метра на квартиры в Белгороде по районам и материалам зданий// Режим доступа: . 2016 г. 